\title{
Actividad inhibitoria del sobrenadante de la bacteria Antártica Pseudomonas sp. M19B en la formación de biopelículas de Flavobacterium psychrophilum 19749
}

Inhibitory activity of Antarctic bacteria Pseudomonas sp. M19B on the biofilm formation of Flavobacterium psychrophilum 19749

\section{Arely Leyton', Homero Urrutia', José Miguel Vidal' ${ }^{1}$, Mery de la Fuente ${ }^{5,6}$, Manuel Alarcón', Germán Aroca ${ }^{3}$, Gerardo González-Rocha ${ }^{4}$ y Katherine Sossa ${ }^{1,2}$}

\author{
${ }^{1}$ Laboratorio de Biopelículas y Microbiología Ambiental, Centro de Biotecnología, Universidad de Concepción, Barrio \\ Universitario s/n, Concepción, Chile. ksossa@udec.cl \\ ${ }^{2}$ Facultad de Ciencias Forestales, Universidad de Concepción, Victoria 631, Barrio Universitario, Concepción, Chile \\ ${ }^{3}$ Facultad de Ingeniería Bioquímica, Universidad de Valparaíso, Av. Brasil № 2147, Valparaíso, Chile \\ ${ }^{4}$ Laboratorio de Investigación en Agentes Antibacterianos, Departamento de Microbiología, Facultad de Ciencias Biológicas, \\ Universidad de Concepción, Concepción, Chile \\ ${ }^{5}$ Laboratorio de Genómica y Biotecnología Aplicada, Departamento de Ingeniería Ambiental y Recursos Naturales, Facultad \\ de Ingeniería, Universidad Católica de la Santísima Concepción, Alonso de Rivera 2850, Concepción, Chile \\ ${ }^{6}$ Departamento de Ciencias Biológicas y Químicas, Facultad de Ciencia, Universidad San Sebastián, General Cruz 1577, \\ Concepción, Chile
}

\begin{abstract}
Flavobacterium psyhrophilum affects farmed salmon and trout worldwide and is the etiological agent of bacterial cold water disease. The treatment of this disease is made with antibiotics. The emergence of resistant strains and its ability to form biofilms have increased the resistance to antibiotics. Considering the diverse bioactivity of Antarctic bacteria, we evaluated the inhibitory effect of compounds secreted by Antarctic bacterial strains on the biofilm formation of F. psychrophilum 19749. 26.9\% of the Antarctic bacterial isolates inhibited strongly the biofilm, the greatest effect was shown by M19B. Proteins (48-56 kDa) secreted by M19B may be related to the inhibition of the biofilm formation of $F$. psychrophilum 19749.
\end{abstract}

Key words: Flavobacterium psychrophilum, biofilms, antarctic bacteria, inhibition

\section{INTRODUCCIÓN}

El patógeno de peces Flavobacterium psychrophilum (Bernardet et al. 1996) es una bacteria psicrófila y agente etiológico de la enfermedad bacteriana del agua fría que afecta a salmones y truchas a nivel mundial (Starliper 2010). Chile es el segundo productor mundial de salmónidos y la enfermedad causada por este patógeno produce un gran impacto económico sobre las principales especies de cultivo como Salmo salar, Oncorhynchus mykiss y Oncorhynchus kisutch (Henríquez-Núñez et al. 2012).

Actualmente, a nivel mundial el control de $F$. psychrophilum se lleva a cabo mediante quimioterapia; en Chile, los principales antibióticos usados para su tratamiento son florfenicol, oxitetraciclina y ácido oxolínico (Henríquez-Núñez et al. 2012).

Sin embargo, el uso excesivo de antibióticos en la acuicultura ha provocado un aumento alarmante de bacterias resistentes disminuyendo la efectividad de los mismos (Cabello 2006).

Otro factor que influye en la resistencia bacteriana a la acción de los antibióticos, es la capacidad de las bacterias de formar biopelículas (Mah \& O'Toole 2001). Una biopelícula es una población de células microbianas que se encuentra adherida a una superficie y embebida en una matriz polimérica extracelular producida por las mismas células (Costerton et al. 1999). En instalaciones acuícolas, las biopelículas son ubicuas y se forman, por ejemplo, en los estanques de cultivo, tuberías de suministro de agua, sistemas de biofiltración, así como también en la superficie de los peces (King et al. 2008). Estudios realizados a la fecha indican que $F$. psychrophilum forma biopelículas in vitro, en vidrio y en pocillos de microplacas de poliestireno (Álvarez et al. 2006, Sundell \& Wiklund 2011) y que las células del patógeno presentes en esta biopelícula muestran una mayor resistencia a los 
antibióticos oxitetraciclina y flumequina, usados comúnmente en acuicultura en comparación a las células planctónicas o de vida libre, es decir, células que no se encuentran asociadas a una superficie (Sundell \& Wiklund 2011). Debido a los problemas asociados a la formación de biopelículas se hace indispensable buscar inéditos mecanismos de control y el territorio Antártico se manifiesta como una fuente de recursos inexplorada en la que se pueden encontrar microorganismos con un potencial uso biotecnológico (Tindall 2004, Papa et al. 2013). Muchas de las investigaciones realizadas con bacterias antárticas se han enfocado en la búsqueda de compuestos antimicrobianos (O'Brien et al. 2004, Lo Giudice et al. 2007) ya que microorganismos antárticos han desarrollado estrategias peculiares de sobrevivencia como la secreción de dichos compuestos para reducir la competencia interespecífica, otorgándoles así ventajas competitivas. Las bacterias antárticas podrían secretar compuestos que afecten el desarrollo de una biopelícula. Por tanto, el objetivo del presente estudio fue evaluar el efecto de compuestos extracelulares producidos por aislamientos obtenidos en la Antártica sobre la formación de la biopelícula de F. psychrophilum 19749.

\section{Materiales Y MÉtodos}

\section{Cepas y condiciones de Cultivo}

En el presente estudio se emplearon un total de 67 sobrenadantes de aislamientos antárticos obtenidos a partir de superficie de rocas, columna de agua, sedimento y rizósfera de musgos, recolectados en la península Fildes, isla Rey Jorge $\left(62^{\circ} 12^{\prime} \mathrm{S}\right.$; $\left.58^{\circ} 57^{\prime} \mathrm{O}\right)$, Territorio Antártico Chileno, durante enero de 2010. Los aislamientos fueron mantenidos a $-80^{\circ} \mathrm{C}$ en caldo Tripticasa de Soya diluido al $50 \%$ y suplementado con glicerol al 20\% (O'Brien et al. 2004). El patógeno $F$. psychrophilum aislado 19749 fue adquirido en Aquagestion Chile Company, y recuperado de un salmón moribundo que presentaba los signos clínicos típicos de la enfermedad del agua fría, como úlceras en la piel y lesiones en la aleta caudal. La identidad de la especie fue confirmada mediante PCR utilizando los partidores PSY1/PSY2 específicos para $F$. psychrophilum (Toyama et al. 1994). El patógeno fue mantenido a $-80^{\circ} \mathrm{C}$ en caldo Triptona Extracto de Levadura y Sales (TYES) compuesto por $\mathrm{MgSO}_{4}\left(0,5 \mathrm{~g} \mathrm{~L}^{-1}\right), \mathrm{CaCl}_{2}\left(0,5 \mathrm{~g} \mathrm{~L}^{-1}\right)$, triptona $\left(4 \mathrm{~g} \mathrm{~L}^{-1}\right)$ y extracto de levadura $\left(0,4 \mathrm{~g} \mathrm{~L}^{-1}\right)$ y suplementado con glicerol al 20\% (Cain \& LaFrentz 2007).

Todos los cultivos bacterianos líquidos, tanto de los aislamientos antárticos como del patógeno, fueron crecidos en caldo TYES a pH 7,2 y en agitación (120 rpm) por $48 \mathrm{~h}$ a $15^{\circ} \mathrm{C}$. La cuantificación celular de $F$. psychrophilum 19749 se realizó mediante recuento en placa con agar TYES diluido al 50 y $1,5 \%$ de agar bacteriológico incubadas a $15^{\circ} \mathrm{C}$ durante 5 días.

\section{ObTENCión de SOBRENADANTES LIBRES DE CÉlulaS}

Los sobrenadantes libres de células de los aislamientos antárticos fueron obtenidos mediante centrifugación de los cultivos celulares luego de 48 h de incubación, cultivos que alcanzaron una densidad óptica de entre 0,9 y 1,2 $\left(\mathrm{DO}_{600}\right)$. Las condiciones de centrifugación fueron $15 \mathrm{~min}, 8000 \mathrm{x} \mathrm{g}, 4^{\circ} \mathrm{C}$ y los sobrenadantes fueron esterilizados filtrando en membranas de acetato de celulosa de $0,2 \mu \mathrm{m}$.

\section{Detección de la aCTIVIDAd INHIBItoria de La FORMACIÓN DE BIOPELÍ́CULAS}

La detección del efecto de los sobrenadantes de los aislamientos antárticos en la formación de biopelículas de F. psychrophilum 19749, se realizó mediante la cuantificación in vitro de la biopelícula utilizando el método de tinción con cristal violeta descrito por Christensen et al. (1985) con modificaciones. Para ello, el cultivo de 48 h de F. psychrophilum 19749, fue ajustado a $\mathrm{DO}_{540}=0,8$ correspondiendo a $1 \times 10^{9} \mathrm{UFC} \mathrm{mL}^{-1}$. Éste fue diluido (1/10) en medio TYES y $15 \mu \mathrm{L}$ de la dilución fueron agregados por triplicado a los pocillos de las microplacas de poliestireno de 96 pocillos (CytoOne, USA) que contenían $60 \mu \mathrm{L}$ del medio TYES diluido al $20 \%$. Posteriormente, se agregaron $75 \mu \mathrm{L}$ del sobrenadante de los aislamientos antárticos. La concentración final del patógeno en los pocillos fue de $1 \times 10^{7} \mathrm{UFC} \mathrm{mL}^{-1}$. Pocillos conteniendo sólo medio de cultivo fueron usados para eliminar factores inespecíficos y pocillos conteniendo medio TYES e inóculo de F. psychrophilum 19749 en ausencia del sobrenadante de los aislamientos antárticos fueron usados como control. La microplaca fue incubada a $15^{\circ} \mathrm{C}$ con $120 \mathrm{rpm}$ de agitación durante 4 días. Luego del tiempo de incubación, la fase planctónica fue retirada y traspasada a otra microplaca para su posterior lectura a $540 \mathrm{~nm}$ en un lector de microplacas (Bio-Tek, USA). Los pocillos con las células remanentes fueron lavados 3 veces con $300 \mu \mathrm{L}$ de agua destilada estéril y las células adheridas fueron fijadas con $250 \mu \mathrm{L}$ de metanol y luego de $15 \mathrm{~min}$ las microplacas fueron vaciadas y secadas al aire durante 45 min (Stepanovic et al. 2004). Posteriormente, $200 \mu \mathrm{L}$ de la solución de cristal violeta al $1 \%(\mathrm{p} / \mathrm{v})$ fueron agregados a cada pocillo. Después de 20 min de agitación, el exceso 
de cristal violeta fue removido, los pocillos fueron lavados 3 veces con $300 \mu \mathrm{L}$ de agua destilada estéril y $250 \mu \mathrm{L}$ de etanol al $70 \%$ (v/v) fueron agregados a los pocillos para solubilizar el cristal violeta adherido a la microplaca. La biopelícula fue cuantificada midiendo la absorbancia del cristal violeta a $595 \mathrm{~nm}$ (Álvarez et al. 2006).

Para seleccionar el aislamiento que presentó el mayor efecto antibiopelícula, se calculó el índice específico de la formación de biopelículas, Specific Biofilm Formation (SBF) (Niu \& Gilbert 2004, Naves et al. 2008); el cual fue calculado de acuerdo a la siguiente fórmula $\mathrm{SBF}=(\mathrm{AB}-$ $\mathrm{CW}) / \mathrm{G}$, en la que $\mathrm{AB}$ es la $\mathrm{DO}_{595}$ de las bacterias adheridas y teñidas con cristal violeta, $\mathrm{CW}$ corresponde a la $\mathrm{DO}_{595}$ de los pocillos teñidos que contenían solamente medio de cultivo sin bacterias y $\mathrm{G}$ que es la $\mathrm{DO}_{540}$ de la fase planctónica, a la cual se le restó el promedio de la $\mathrm{DO}_{540}$ de los pocillos que contenían solamente medio de cultivo. El criterio establecido por Naves et al. (2008), según el cual las células son fuertes productoras de biopelículas si $\mathrm{SBF}>1$ y débiles si $\mathrm{SBF} \leq 1$ fue modificado estableciendo que el efecto de los aislados antárticos en la formación de biopelículas fue fuertemente inhibidor si $\mathrm{SBF} \leq 1$ y débilmente inhibidor y/o sin efecto si $\mathrm{SBF}>1$. De los sobrenadantes de los aislamientos que presentaron un efecto fuertemente inhibidor de la formación de biopelículas, se seleccionó el sobrenadante del aislamiento que presentó el valor de SBF más bajo. Finalmente, se consideró un efecto inhibidor de crecimiento si el sobrenadante impidió el crecimiento planctónico del patógeno.

\section{IDENTIFICACIÓN MOLECULAR DE LA CEPA BACTERIANA INHIBIDORA DE LA BIOPELÍCULA}

El aislamiento que presentó el mayor efecto antibiopelícula fue identificado mediante técnicas moleculares, para ello se extrajo el ADN genómico mediante el kit de extracción de ADN, ZR Fungal/Bacterial DNA MiniPrep (Zymo Research, USA), siguiendo las indicaciones del proveedor. El ADN extraído se usó como templado para la amplificación por PCR con los partidores 9-27f y 1542r, específicos para ADNr 16S del Dominio Bacteria (Joulian et al. 1998, Weisburg et al. 1991). El producto de PCR (1.287 pb) fue secuenciado por Macrogen Inc. (Seúl, Korea). La secuencia obtenida se ingresó en el programa de alineamiento de secuencias BLAST (Basic Local Alignment Search Tool) (Altschul et al. 1990). La confirmación de género se realizó mediante pruebas fenotípicas que incluyeron tinción de Gram, fermentación de glucosa, test de catalasa y oxidasa así como determinación de la movilidad.
Detección de PRoteínas EN EL SOBRENadante Y SU EFECTO SOBRE LA FORMACIÓN DE BIOPELÍCULAS

Para detectar proteínas responsables de la actividad antibiopelícula, el sobrenadante libre de células del aislado seleccionado fue concentrado por ultrafiltración en una centrífuga $\left(1 \mathrm{~h}, 8000 \mathrm{x} \mathrm{g}, 4^{\circ} \mathrm{C}\right)$ con un dispositivo de filtro de membrana con poro de corte de $3.000 \mathrm{Da}$ (Amicon Ultra-15, 3K, Millipore). El retenido fue visualizado en un gel desnaturalizante SDS-PAGE. Las muestras fueron mezcladas con buffer de carga $(20 \mu \mathrm{L}$ de muestra y $8 \mu \mathrm{L}$ de buffer de carga) y se procedió a realizar su desnaturalización térmica calentando la muestra a $100^{\circ} \mathrm{C}$ durante $5 \mathrm{~min}$. Luego, $20 \mu \mathrm{L}$ de la mezcla fueron analizadas usando un gel de poliacrilamida al $16 \%$. La electroforesis se llevó a cabo a $150 \mathrm{~V}$ durante $2,5 \mathrm{~h}$ y el buffer de corrida de electroforesis contenía Tris $1 \mathrm{M}$, tricina $1 \mathrm{M}$ y SDS $1 \%$ $(\mathrm{p} / \mathrm{v}), \mathrm{pH} 8,25$. Para su visualización, los geles fueron teñidos con azul de Comassie.

La cuantificación de las proteínas presentes en el sobrenadante del aislamiento seleccionado se realizó con el kit Pierce BCA Protein Assay Kit (Thermo Scientific, USA), siguiendo las indicaciones del proveedor, para posteriormente realizar ensayos de inhibición de formación de biopelículas, los cuales se realizaron en microplacas y con distintas concentraciones proteicas. Para ello, un cultivo de 48 h de F. psychrophilum 19749, fue ajustado a $\mathrm{DO}_{540}=0,8$ correspondiendo a $10^{9} \mathrm{UFC} \mathrm{mL}^{-}$ ${ }^{1}$ para quedar en el pocillo una concentración del patógeno de 1 x $10^{7}$ UFC $\mathrm{mL}^{-1}$. A los pocillos de las microplacas se les agregó el inóculo del microorganismo, medio TYES diluido al $20 \%$ y distintos volúmenes del concentrado proteico, siendo evaluadas las siguientes concentraciones finales de proteínas: 0,$5 ; 1,0 ; 1,5 ; 2,0 ; 2,5$ y $3,0 \mathrm{mg} \mathrm{mL}^{-1}$ (volumen final $150 \mu \mathrm{L}$ ). La microplaca fue incubada a $15^{\circ} \mathrm{C}$ con $120 \mathrm{rpm}$ de agitación durante 4 días. La cuantificación de la biopelícula se realizó mediante la técnica tinción con cristal violeta descrito anteriormente.

Se realizó un análisis ANOVA de una sola vía $(P<$ $0,050)$ entre los tratamientos y el control y una comparación de medias mediante el test de Dunnett (Cady et al. 2012).

\section{Resultadoos Y Discusión}

De los sobrenadantes obtenidos de los 67 aislamientos estudiados, 18 de ellos (26,9\%) exhibieron un efecto antibiopelículas fuerte, mientras que 17 de ellos $(25,4 \%)$ no presentaron efecto antibiopelículas (Tabla 1). 
Tabla 1. Efecto de sobrenadantes de aislados antárticos en la formación de biopelículas de Flavobacterium psychrophilum 19749 según valores de SBF* / Effect of the supernatant produced by antarctic bacterial isolates on the biofilm formation of Flavobacterium psychrophilum 19749 according to the SBF*value

\begin{tabular}{lccc}
\hline $\begin{array}{c}\text { Clasificación del efecto de los sobrenadantes en la } \\
\text { formación de biopelículas de Flavobacterium } \\
\text { psychrophilum }\end{array}$ & $\begin{array}{c}\mathrm{N}^{\circ} \text { de aislados } \\
\text { antárticos }\end{array}$ & $\%$ & $\begin{array}{c}\text { Rango de } \\
\text { SBF* }\end{array}$ \\
\hline Anti- biopelícula & 18 & 26,9 & $0,19-0,86$ \\
Sin efecto & 17 & 25,4 & $4,2-5,9$ \\
Inhibidor del crecimiento & 32 & 47,7 & ND \\
\hline
\end{tabular}

*SBF, Specific Biofilm Formation; ND. No determinado

Los sobrenadantes de los 32 aislamientos restantes $(47,7 \%)$ mostraron un efecto inhibidor del crecimiento planctónico de F. psychrophilum 19749, lo que no permitió metodológicamente determinar el índice SBF en este grupo de aislamientos.

De los 18 sobrenadantes que mostraron el efecto antibiopelículas fuerte, se eligió el sobrenadante del aislamiento M19B como el mejor representante ya que exhibió el menor índice de formación de biopelículas $(\mathrm{SBF}=0,19)$ comparado con el control $(\mathrm{SBF}=4,9)$, por lo tanto, fue el sobrenadante que inhibió en mayor medida la formación de la biopelícula de F. psychrophilum 19749 (Fig. 1).

Respecto de la identificación molecular del aislamiento M19B, se determinó que el fragmento de ADNr 16S amplificado, secuenciado y depurado presentó 99\% de identidad con la especie Pseudomonas fragi (número de acceso GenBank AB685646.1). La secuencia obtenida en este trabajo ( $824 \mathrm{pb}$ ) fue ingresada en el GenBank con el código de acceso KC854411. Los resultados de las pruebas fenotípicas que permitieron confirmar la pertenencia del aislamiento M19B al género Pseudomonas fueron catalasa y oxidasa positiva, incapacidad de fermentar carbohidratos, presencia de bacilos cortos Gram negativos y movilidad positiva.

El sobrenadante concentrado fue utilizado para la realización de un gel desnaturalizante SDS-PAGE para detectar la presencia de proteínas en el sobrenadante del aislamiento seleccionado y luego evaluar su posible efecto en la actividad inhibitoria. El análisis del gel mostró proteínas de tamaño entre 46 y $58 \mathrm{kDa}$ en el sobrenadante del aislamiento M19B (Fig. 2A).

El sobrenadante concentrado fue utilizado para cuantificar las proteínas presentes mediante un kit de cuantificación proteica y se determinó una concentración de 3,6 $\mathrm{mg} \mathrm{mL}^{-1}$ de proteínas. Diluciones entre 0,5 y $1,5 \mathrm{mg}$ $\mathrm{mL}^{-1} \mathrm{de}$ estas proteínas tuvieron un efecto inhibitorio fuerte $(\mathrm{SBF}<1)$ en la formación de la biopelícula de $F$. psychrophilum 19749, mientras que concentraciones superiores a $1,5 \mathrm{mg} \mathrm{mL}^{-1}$, si bien inhibieron la formación de biopelículas comparado con el control, esta inhibición se produjo por un efecto inhibitorio sobre el crecimiento planctónico del patógeno $(P<0,05)$ (Fig. 2B).

Los problemas asociados a la formación de biopelículas en acuicultura se relacionan con la persistencia de los microorganismos en el ambiente ya que provocan la exposición recurrente de los peces a los agentes patógenos (King et al. 2008) y además, se asocian con la elevada resistencia de una biopelícula al tratamiento con antimicrobianos (Mah \& O'Toole 2001, Davies 2003, Jefferson 2004). El patógeno de peces $F$. psychrophilum forma biopelículas, por lo que es de suma importancia interferir en su formación. En este estudio se determinó que cerca de un tercio de los aislamientos antárticos evaluados secretaron compuestos con actividad inhibitoria sobre la formación de biopelículas de F. psychrophilum 19749. A la fecha, sólo hay un reporte de un aislamiento antártico identificado como Pseudoalteromonas haloplanktis, productora de compuestos inhibidores de biopelículas, en este caso de la biopelícula de Staphylococcus epidermidis (Papa et al. 2013). Cabe destacar que cerca de la mitad de los aislamientos antárticos produjo compuestos que inhibieron el crecimiento en fase planctónica de $F$. psychrophilum 19749, por lo que sumado al efecto antibiopelículas, un $75 \%$ del total de los sobrenadantes presentó algún efecto sobre $F$. psychrophilum 19749, probablemente debido a que las condiciones extremas de la región obligan a estos microorganismos a secretar 


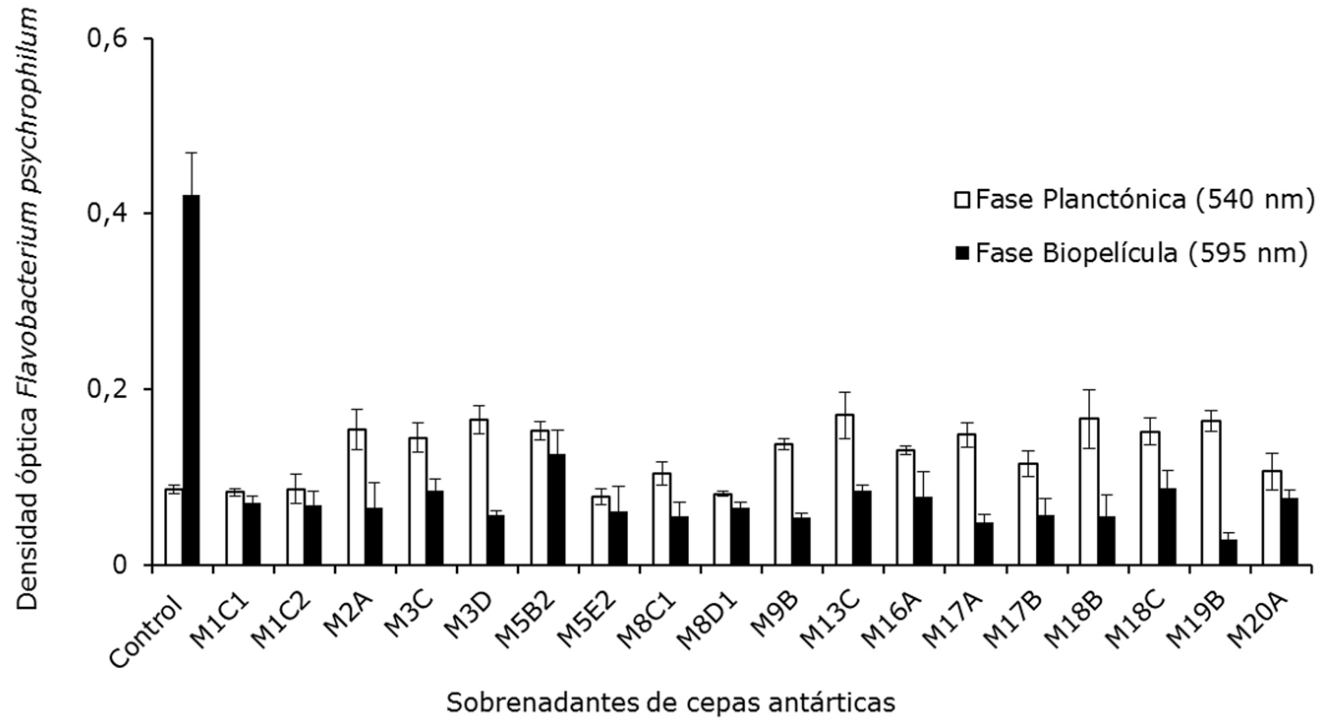

Figura 1. Efecto antibiopelículas de los sobrenadantes de los aislamientos antárticos sobre F. psychrophilum 19749. Todas las densidades ópticas de la biopelícula presentan diferencias significativas $(P<0,05)$ con respecto al control que corresponde al patógeno y medio de cultivo sin sobrenadante / Anti biofilm effect of the supernatants of Antarctic bacterial isolates on $F$. psychrophilum 19749. All optical densities of the biofilm show significant differences $(P<0.05)$ compared with the control that corresponds to the pathogen and culture medium without supernatant

A)

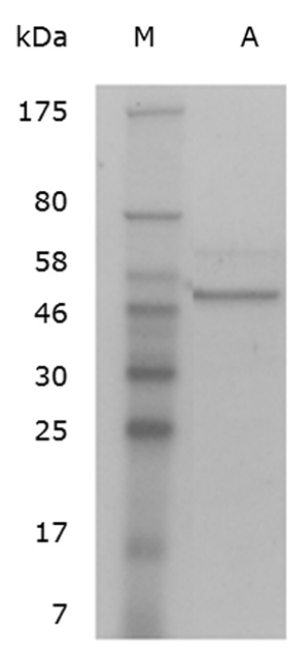

B)

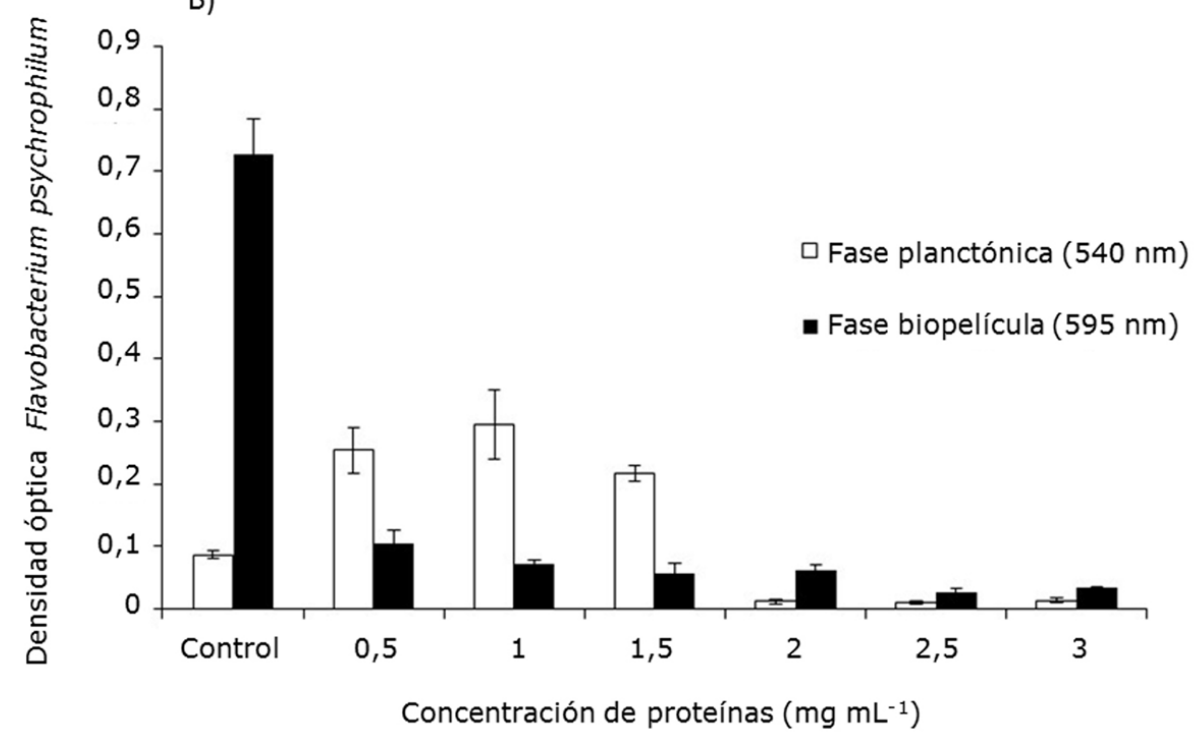

Figura 2. A) Electroforesis en gel SDS-PAGE (16\% acrilamida) de proteínas presentes en el sobrenadante de Pseudomonas sp. M 19B. M: Marcador de peso molecular; A: sobrenadante de Pseudomonas sp. M19B. B) Efecto de distintas concentraciones proteicas presentes en el sobrenadante de Pseudomonas sp. M 19B sobre la formación de biopelículas de F. psychrophilum 19749. El control corresponde al patógeno y medio de cultivo sin sobrenadante / A) Gel Electrophoresis SDS-PAGE (16\% acrylamide) of proteins present in the supernatant of Pseudomonas sp. M19B. M: molecular weight marker; A: Pseudomonas sp. M19B supernatant. B) Effect of different protein concentrations present in the supernatant of Pseudomonas sp. M19B on the biofilm formation of F. psychrophilum 19749. The control corresponds to the pathogen and medium without supernatant 
compuestos antimicrobianos para hacer frente a potenciales competidores (Lo Giudice et al. 2007). El aislamiento antártico que presentó el mayor efecto antibiopelícula fue M19B, el cual pertenece al género Pseudomonas, género que ha sido utilizado con fines de biocontrol en acuicultura (Bly et al. 1997) y específicamente en el biocontrol de $F$. psychrophilum (Korkea-aho et al. 2011, Strom-Bestor \& Wiklund 2011) ya que forma parte de la microbiota normal de los peces (Smith \& Davey 1993, Bly et al. 1997). El análisis de la secuencia sugiere que el aislamiento pertenecería a la especie Pseudomonas fragi, una bacteria psicrófila, sin embargo, se requiere realizar un ensayo de hibridación ADN-ADN para confirmar la identidad exacta de la especie.

Los compuestos activos con efecto antibiopelículas presentes en el sobrenadante de Pseudomonas sp. M19B no pudieron ser extraídos con los disolventes orgánicos de diferente polaridad como hexano, diclorometano y acetato de etilo (datos no mostrados), lo que indica que los compuestos activos no serían compuestos apolares. Por otro lado, los resultados preliminares de este estudio sugieren que en la actividad antibiopelículas de Pseudomonas sp. M19B participarían proteínas secretadas por la cepa, las cuales se encuentran en un rango de peso molecular de entre 46 y $58 \mathrm{kDa}$. Además, cuando se evaluó el efecto de distintas concentraciones proteicas en la formación de la biopelícula, se produjo una inhibición dosis-dependiente de ésta, por lo que podemos sugerir que el efecto inhibitorio fue debido a las proteínas presentes en el sobrenadante de Pseudomonas sp. M19B. En este punto, se ha reportado la actividad antibiopelícula de compuestos proteicos como en el caso de una proteína de $48 \mathrm{kDa}$ secretada por Streptococcus intermedius, la cual fue identificada como una arginina desaminasa, proteína que impidió la formación de la biopelícula de Porphyromonas gingivalis mediante la represión de la expresión de los genes que codifican las principales subunidades proteicas de los dos tipos de fimbrias presentes en su superficie y responsables de la adherencia y posterior formación de biopelículas (Christopher et al. 2010). Así también, péptidos y/o proteínas secretados por una cepa del género Streptomyces interfirieron en la formación de la biopelícula de $P$. aeruginosa (Kim et al. 2012).

Sin embargo, es necesario descartar la acción sinérgica de otros compuestos presentes en el sobrenadante con efecto en la formación de biopelículas, como por ejemplo, polisacáridos, los cuales han mostrado un efecto antibiopelículas (Rendueles et al. 2013). Además, se deben purificar las proteínas secretadas por Pseudomonas sp. M19B y, por un lado, realizar estudios conducentes a comprobar el efecto antibiopelículas de las proteínas secretadas mediante técnicas de microscopía y por otro, evaluar el efecto de dichas proteínas en un mayor número de especies de F. psychrophilum. Si bien es cierto, este estudio entrega resultados preliminares, es punto de partida para investigaciones dirigidas a interferir en la formación de biopelículas de F. psychrophilum.

\section{Agradecimientos}

Este estudio fue posible gracias al financiamiento del Proyecto FONDECYT 1101009, al Proyecto INACH T-1708 a cargo del Dr. Gerardo González Rocha y al Proyecto INACH M_09-11 de apoyo a la realización de tesis de postgrado.

\section{LITERATURA CITADA}

Altschul SF, W Gish, W Miller, EW Myers \& DJ Lipman. 1990. Basic local alignment search tool. Journal of Molecular Biology 215(3): 403-410.

Álvarez B, P Secades, M Prieto, MJ McBride \& JA Guijarro. 2006. A mutation in Flavobacterium psychrophilum tlpB inhibits gliding motility and induces biofilm formation. Applied and Environmental Microbiology 72(6): 4044-4053.

Bernardet JF, P Segers, M Vancanneyt, F Berthe, K Kersters \& P Vandamme. 1996. Cutting a gordian knot: emended classification and description of the genus Flavobacterium, emended description of the family Flavobacteriaceae, and proposal of Flavobacterium hydatis nom. nov. (Basonym, Cytophaga aquatilis Strohl \& Tait 1978). International Journal of Systematic Bacteriology 46: 128-148.

Bly JE, SA Quiniou, LA Lawson \& LW Clem. 1997. Inhibition of Saprolegnia pathogenic for fish by Pseudomonas fluorescens. Journal of Fish Disease 20(1): 35-40.

Cabello FC. 2006. Heavy use of prophylactic antibiotics in aquaculture: a growing problem for human and animal health and for the environment. Environmental Microbiology 8(7): 1137-1144.

Cady NC, KA McKean, J Behnke, R Kubec, AP Mosier, SH Kasper, DS Burz \& RA Musah. 2012. Inhibition of biofilm formation, quorum sensing and infection in Pseudomonas aeruginosa by natural products-inspired organosulfur compounds. PloS One 7(6): e38492. <doi:10.1371/ journal.pone.0038492>

Cain KD \& BR LaFrentz. 2007. Laboratory maintenance of Flavobacterium psychrophilum and Flavobacterium columnare. In: Coico R, T Kowalik, JM Quarles, B Stevenson, RK Taylor \& AE Simon (eds). Current Protocols in Microbiology, pp. 13B.1.1-13B.1.12. John Wiley and Sons, Hoboken. 
Christensen GD, WA Simpson, JJ Younger, LM Baddour, FF Barrett, DM Melton \& EH Beachey. 1985. Adherence of coagulase-negative Staphylococci to plastic tissue culture plates: a quantitative model for the adherence of Staphylococci to medical devices. Journal of Clinical Microbiology 22(6): 996-1006.

Christopher AB, A Arndt, C Cugini \& ME Davey. 2010. A streptococcal effector protein that inhibits Porphyromonas gingivalis biofilm development. Microbiology 156(11): 3469-3477.

Costerton JW, PS Stewart \& EP Greenberg. 1999. Bacterial biofilms: a common cause of persistent infections. Science 284(5418): 1318-1322.

Davies D. 2003. Understanding biofilm resistance to antibacterial agents. Nature Reviews Drug Discovery 2(2): 114-122.

Henríquez-Núñez H, O Evrard, G Kronvall \& R AvendañoHerrera. 2012. Antimicrobial susceptibility and plasmid profiles of Flavobacterium psychrophilum strains isolated in Chile. Aquaculture 354: 38-44.

Jefferson K. 2004. What drives bacteria to produce a biofilm? FEMS Microbiology Letters 236(2): 163-173.

Joulian C, B Ollivier, BKC Patel \& PA Roger. 1998. Phenotypic and phylogenetic characterization of dominant culturable methanogens isolated from ricefield soils. FEMS Microbiology Ecology 25(2): 135-145.

Kim YG, JH Lee, CJ Kim, JC Lee, YJ Ju, MH Cho \& J Lee. 2012. Antibiofilm activity of Streptomyces sp. BFI 230 and Kribbella sp. BFI 1562 against Pseudomonas aeruginosa. Applied Microbiology and Biotechnology 96(6): 1607 1617.

King RK, GJ Flick Jr, SA Smith, MD Pierson, GD Boardman \& CW Coale Jr. 2008. Response of bacterial biofilms in recirculating aquaculture systems to various sanitizers. Journal of Applied Aquaculture 20(2): 79-92.

Korkeaaho, TL, J Heikkinen, KD Thompson, A von Wright \& B Austin. 2011. Pseudomonas sp. M174 inhibits the fish pathogen Flavobacterium psychrophilum. Journal of Applied Microbiology 111(2): 266-277.

Lo Giudice A, V Bruni \& L Michaud. 2007. Characterization of Antarctic psychrotrophic Bacteria with antibacterial activities against terrestrial microorganisms. Journal of Basic Microbiology 47(6): 496-505.

Mah TFC \& GA O'Toole. 2001. Mechanisms of biofilm resistance to antimicrobial agents. Trends in Microbiology 9(1): 34-39.
Naves P, G del Prado, L Huelves, M Gracia, V Ruiz, J Blanco, G Dahbi, M Blanco, M Ponte \& F Soriano. 2008. Correlation between virulence factors and in vitro biofilm formation by Escherichia coli strains. Microbial Pathogenesis 45(2): 86-91.

Niu C \& ES Gilbert. 2004. Colorimetric method for identifying plant essential oil components that affect biofilm formation and structure. Applied and Environmental Microbiology 70(12): 6951-6956.

O'Brien A, S Richard, N Russell \& S Roller. 2004. Antarctic bacteria inhibit growth of food-borne microorganisms at low temperatures. FEMS Microbiology Ecology 48(2): 157167.

Papa R, E Parilli, F Sannino, G Barbato, ML Tutino, M Artini \& L Selan. 2013. Anti-Biofilm activity of the Antarctic marine bacterium Pseudoalteromonas haloplanktis TAC125. Research in Microbiology 164(5): 450-456.

Rendueles O, JB Kaplan \& JM Ghigo. 2013. Antibiofilm polysaccharides. Environmental Microbiology 15(2): 334346.

Smith P \& S Davey. 1993. Evidence for the competitive exclusion of Aeromonas salmonicida from fish with stressinducible furunculosis by a fluorescent pseudomonad. Journal of Fish Diseases 16(5): 521-524.

Starliper C. 2010. Bacterial coldwater disease of fishes caused by Flavobacterium psychrophilum. Journal of Advanced Research 2(2): 97-108.

Stepanovic S, I Cirkovic, L Ranin \& M Svabic-Vlahovic. 2004. Biofilm formation by Salmonella spp. and Listeria monocytogenes on plastic surface. Letters in Applied Microbiology 38(5): 428-432.

StrömBestor M \& T Wiklund. 2011. Inhibitory activity of Pseudomonas sp. on Flavobacterium psychrophilum, in vitro. Journal of Fish Diseases 34(4): 255-264.

Sundell K \& T Wiklund. 2011. Effect of biofilm formation on antimicrobial tolerance of Flavobacterium psychrophilum. Journal of Fish Diseases 34(5): 373-383.

Tindall BJ. 2004. Prokaryotic diversity in the Antarctic: the tip of the iceberg. Microbial Ecology 47(3): 271-283.

Toyama T, K Kita-Tsukamoto \& H Wakabayashi. 1994. Identification of Cytophaga psychrophila by PCR targeted 16S ribosomal RNA. Fish Pathology 29: 271-275.

Weisburg W, S Barns, D Pelletier \& D Lane. 1991. 16S ribosomal DNA amplification for phylogenetic study. Journal of Bacteriology 173(2): 697-703.

Recibido el 29 de julio de 2014 y aceptado el 7 de mayo de 2015

Editor: Claudia Bustos D. 